\title{
Research Paper: Explaining the Obsessive-compulsive Symptoms Based on Cognitive Flexibility and Social Cognition
}

\author{
Shima Pajouhinia ${ }^{1}$,, Yalda Abavisani $^{2}$ (1), Zahra Rezazadeh ${ }^{1^{*}}$ (1) \\ 1. Departeman of Clinical Psychology, Faculty of Psychology and Educational Sciences, Allameh Tabataba 'i University, Tehran, Iran \\ 2. Department of Counseling, Quchan Brahnch, Islamic Azad University, Quchan, Iran.
}

\begin{tabular}{|c|c|}
\hline $\begin{array}{l}\text { Use your device to scan } \\
\text { and read the article online }\end{array}$ & \\
\hline 口isting & $\begin{array}{l}\text { Citation: Pajouhinia, Sh., Abavisani, Y., \& Rezazadeh, Z. (2020). Explaining the Obsessive-compulsive Symptoms Based on } \\
\text { Cognitive Flexibility and Social Cognition. Journal of Practice in Clinical Psychology, 8(3), 233-242. https://doi.org/10.32598/ } \\
\text { jpcp.8.3.10.717.1 }\end{array}$ \\
\hline nitisis & dol ${ }^{\circ}$ https://doi.org/10.32598/jpcp.8.3.10.717.1 \\
\hline
\end{tabular}

\section{(i) (\$)}

Article info:

Received: 23 Oct 2019

Accepted: 12 Feb 2020

Available Online: $01 \mathrm{Jul} 2020$

Keywords:

Obsessive, Compulsive disorder, Flexibility, Cognition

\section{ABSTRACT}

Objective: Cognitive flexibility and social cognition are the appropriate models for understanding psychological problems, through which people can meet various challenges. The aim of this study was to investigate the relationship between cognitive flexibility and social cognition with obsessive-compulsive symptoms among female students at Allameh Tabataba'i University.

Methods: This cross-sectional study was done on 200 students female students at Allameh Tabataba'i University in Tehran studying in the academic year 2018-2019 selected by random multiple cluster sampling method. The used tools were cognitive flexibility inventory, student social cognition questionnaire, and obsessive-compulsive symptoms inventory.

Results: There was a negative significant correlation between the total score of obsessivecompulsive symptoms with cognitive flexibility and social cognition. In addition, the results of multiple regression analysis showed that cognitive flexibility and social cognition can explain obsessive-compulsive symptoms in students.

Conclusion: Studying cognitive flexibility and social cognition is an efficient method to understand the underlying factors associated with obsessive-compulsive symptoms. Evaluation of these factors can be useful in the prevention and treatment of these symptoms. 


\section{Highlights}

- The study of cognitive flexibility and social cognition is effective in understanding the factors associated with obsessive-compulsive symptoms.

- Assessing these factors is helpful in preventing and treating the symptoms of this disorder.

\section{Plain Language Summary}

This study investigated the relationship between cognitive flexibility and social cognition with obsessive-compulsive symptoms in female students. The statistical population of this study was comprised of all female students at Allameh Tabataba'i University in Tehran and selected using a cluster sampling method. Cognitive flexibility inventory, student social cognition questionnaire, and Maudsley obsessive-compulsive symptoms inventory were used to collect data. The results showed that obsessive-compulsive symptoms have a significant negative relationship with cognitive flexibility and social cognition. Thus, cognitive flexibility and social cognition can explain and predict obsessive-compulsive symptoms in students. The study of cognitive flexibility and social cognition is effective to understand the factors associated with obsessive-compulsive symptoms and can help to prevent and treat these symptoms.

\section{Introduction}

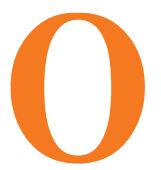

bsessive-Compulsive Disorder (OCD) is a common psychiatric disorder defined as obsession or compulsion, or both, which causes marked disturbances or interferes with daily functioning. Obsessions are repetitive thoughts, desires, or ideas that are experienced in a disturbing and unwanted way. Obsessions are repetitive behaviors or mental acts that a person feels perform in response to an obsession in a ritualistic way (American Psychiatric Association, 2013). The content of obsessions and compulsions varies from person to person; however, recent research on the multidimensional structure of OCD identified 4 common symptoms: 1. Obsession with contamination /compulsion to wash; 2. Accountability for annoying obsessions/compulsion to check; 3. Unacceptable thoughts (sexual, religious, or aggressive); 4. obsessions of symmetry, completion or order/coercion adjustment (Abramovitch, Abramowitz \& Mittelman, 2013). Therefore, OCD is essentially a cognitive and emotional processing disorder, in which individuals experience disturbing thoughts, ideas, mental images, and unwanted impulses causing anxiety, which are difficult to eliminate (Ghamarigivi, 2013).

OCD is one of the most serious mental health problems that annually imposes huge economic and social costs on society (Barlow, 2004). Epidemiological studies in Iran have indicated the high prevalence of this disorder and have shown that this disease can cause significant disruption in normal life, work function, normal social activities, or personal relationships (Hashemloo, Safaralizadeh, Bagheriyeh \& Motearefi, 2014). However, over $90 \%$ of people in the society experience symptoms of obsessions and compulsions with the same quality and shape as people with OCD (Purdon \& Clark, 1993) doubling the significance and necessity of recognizing the symptoms of obsessions and compulsions.

On the other hand, Bry'nska believes that the prevalence rate of OCD and the age of onset of the disease is different in men and women and men develop the disorder earlier than women, but the number of women with OCD is higher than men (Bry'nska, 1997). OCD in the Iranian population is more in women than men (Ghafeleh Bashi, Sarichloo, Mousavi \& Salehi, 2014). The results of Riggs and Foa research also showed that slightly more than half of people with OCD are women (Riggs \& Foa, 1993). Perhaps, the reason for the difference in prevalence can be found in women's physiology and the type of responsibilities. Women naturally experience three physical characteristics in their life that do not exist in men: menstruation, pregnancy, and menopause. Each of these stages is followed by periods of stress and anxiety.

Women, on the other hand, live in the same world as men and are responsible for their family members. Due to such anxieties in women, which is the cause of OCD, the high prevalence of this disorder seems to be normal in women (Khosravi \& Naseri, 2017). Also, it seems that neglecting this disease and misconceptions that are sometimes considered as normal behaviors and even positive human behaviors, especially among women, 
have delayed its diagnosis and treatment, which will lead to irreparable serious damages. This confirms the urgent need to take preventive actions in this regard.

Studies in recent decades have shown great interest in investigating the neurocognitive factors in OCD and have paid special attention to the structures, processes, and cognitive content of OCD in the field of research and treatment of OCD (Abramovitch et al., 2013; Cameron et al., 2019). Various studies have emphasized the fundamental role of executive functions in the etiology and persistence of OCD symptoms (Hekmati, 2012). The ability to manage the intervening components in goal-oriented behaviors and predicting the consequences of performance is called the executive function. A group of researchers uses the concept of how and why human behaviors to explain executive functions, and another group categorizes these functions into different cognitive domains, including planning and organizing behavior, response inhibition, performance continuity, dominance reduction, and ability to initiate performance (Ardila, 2008). Cognitive flexibility is one of the executive functions involved in OCD (Abramovitch et al., 2013; Ozcan, Ozer \& Yagcioglu, 2016; Snyder, Kaiser, Warren \& Heller, 2015), which is the capacity to change and modify active memory and attention, and choose a response to internal and external demands (Deák \& Wiseheart, 2015). Cognitive flexibility is the ability to change cognitive sets to adapt to changing environmental stimuli, i.e. abilities, such as changing one's perspective or adapting oneself to new laws, requirements, or environmental conditions (Dennis \& Vander Wal, 2010).

Poor performance in tasks that require flexible behavior is often one of the specific clinical symptoms of OCD (Abramovitch et al., 2013; Vaghi et al., 2017). Based on some studies, people with OCD suffer from disorders in cognitive flexibility (Vaghi et al., 2017; Okasha et al., 2000; Lawrence et al., 2006; Bannon, Gonsalvez, Croft, \& Boyce, 2006; Bohne et al., 2005; Britton et al., 2010; Bigdeli, Badin \& Sabahi, 2017; Rosa-Alcázar et al., 2020). Studies have shown that the integrity of basal ganglia and their relationship to the frontal cortex plays a vital role in the emotional, cognitive, and motor flexibility required for goal-oriented behaviors (Vaghi et al., 2017).

Also, evidence from obsession neuroimaging studies suggests that performance in cognitive flexibility tests may be moderated by the dorsolateral prefrontal cortex and frontal-striatal circuitry branches (Vaghi et al., 2017; Saxena \& Rauch, 2000; Francazio \& Flessner, 2015). These brain areas are known as potentially dysfunctional areas in disorders characterized by OCD-related behav- iors. For example, a study of patients with OCD suggested that performance on cognitive flexibility tests was associated with a decrease in frontal-striatal circuitry branches (Britton et al., 2010). These findings suggest that cognitive flexibility may be an important structural indicator for understanding the etiology of OCD-related behaviors from a biological and phenotypic perspective (Francazio \& Flessner, 2015). However, the results are inconsistent, and other findings do not show a difference between OCD individuals and the control group in cognitive flexibility tasks (Abbruzzese, Ferri \& Scarone, 1997; Moritz et al., 2001; Moritz et al., 2002).

Social cognition is another important aspect of neurocognition involved in obsessive-compulsive symptoms (Misir, Bora \& Akdede, 2018; Darvishi, Mahmoud Alilou, Bakhshipour, Farnam \& Bahramkhani, 2013; Movahedi, Khodadadi \& Mohammadzadegan, 2014). Social cognition is the ability to recognize oneself and the emotions of other people, and the capability to infer their mental states from the tone, facial, and body states, the ability to argue about mental states, empathy, and humor processing, understanding the meaning of their behavior, social signs, and social adaptation, using the rules and knowledge related to social affairs in order to interact with peers and managing one's emotions in interpersonal relationships (Pinkham et al., 2014; Reyhani, Kamari, Zarei \& Nejati, 2017).

Social cognition refers to the understanding, interpretation, and processing of all information pertaining to the individual's environment and social relationships, and comprises a set of structures, such as the theory of mind, mentalizing, empathy, social perception, social knowledge, emotion processing, self-esteem, self-concept, attributional biases, etc. (Sharp, Fonagy \& Goodyer, 2008). According to Burns (Burns, 2006), under the pressure of social choice, human ancestors developed a specialized neural network responsible for social cognition and adaptive interpersonal behavior, which is technically called the social brain. Therefore, the social brain refers to the network of areas of the brain underlying these processes (Burns, 2006).

Social cognition impairment plays a role in the pathology of many psychiatric disorders (Cotter et al., 2018). Based on studies, social cognitive impairment may be common in patients with basal ganglia abnormalities, such as Huntington disease, Parkinson's disease, and perhaps OCD (Bodden, Dodel \& Kalbe, 2010). A study by Misir et al. (2018) showed that patients with OCD showed significant impairment in the auditory-social and perceptual-social aspects of the theory of mind. In a study by Grisham et al. (Quoted by Movahedi et al., 
2014), severe symptoms of the disorder were associated with a decreased ability of the theory of mind and reduced accuracy in deciphering the hate emotion.

This study indicated that obsessive-compulsive symptoms are related to the difficulty in understanding the views of others and deciphering the expression of faces. A study by Kang et al. (Kang, Namkoong, Yoo, Jhung \& Kim, 2012) showed that patients with OCD had a significant reduction in perspective-taking compared with the control group and experienced perceptual bias of hate in response to ambiguous facial expressions. In the study by Aigner et al. (2007), patients with OCD had impairment in emotion recognition (as a component of social cognition) compared with the control group (Aigner et al., 2007). Some studies have found no evidence of social pathology in OCD patients; for example, in the study by Mavrogiorgou et al. (2016), the basic abilities of social cognition in OCD patients did not significantly than the control group.

The wide prevalence and complexity of OCD on the one hand, and its individual, familial, and social complications, on the other hand, have made theorists, researchers, and clinical specialists evaluate various aspects of these disorders and theorize about their pathology, prevention, and treatment and offer different models; however, its vast dimensions are still unknown. To predict and control this disorder, it is necessary to identify its associated factors. Due to the role of cognitive flexibility and social cognition in the symptoms of OCD and because the age of onset of OCD is often up to 35 years and most patients are women (American Psychiatric Association, 2013; Forray, Focseneanu, Pittman, McDougle \& Neill Epperson, 2010) and also considering that the physical and mental health of women as future mothers is one of the most fundamental factors in creating a favorable atmosphere in the family as the first base of education, in the present study, the role of these variables in the emergence and persistence of obsessive-compulsive symptoms was investigated.

Thus, this study lays the proper groundwork for therapists to design strategies to reduce obsessive-compulsive symptoms. Finally, the novelty of the research topic as well as the lack of similar topics in international studies and those conducted in Iran can indicate the need for this research. Accordingly, the present study aimed at answering whether there is a relationship between cognitive flexibility and social cognition with obsessivecompulsive symptoms in students, and also whether cognitive flexibility and social cognition are able to predict these symptoms.

\section{Methods}

This research was a cross-sectional study using a bivariate correlation and multivariate regression. The statistical population included all female students of Allameh Tabatabai University in Tehran who were studying in the academic year 2018-2019. A sample of 200 female students was selected by multi-stage random sampling, of whom 36 cases $(18 \%)$ were married and 164 cases $(82 \%)$ were single. The participants aged $19-30$ years with a mean age of $21.73 \pm 2.65$ years. The sample size was determined bases on the minimum value for relational research (Delavar, 2000). Accordingly, first, the total number of faculties in Allameh Tabatabai University was determined, of which three faculties were randomly selected, and then four classes were identified from each of the selected faculties and the questionnaires were distributed among female students in these classes. After distributing the questionnaires and informing the subject of the research, and in the case of subjects' consent to cooperate, the researcher provided the necessary explanations about how to complete the questionnaires. The researcher also assured the subjects that the results of the questionnaires would be used only for this research and that their answers would remain confidential.

\section{Maudsley Obsessive-Compulsive Inventory (MOCI)}

This test had 32 items (right or wrong) and is designed to measure the symptoms of OCD. MOCI determines a variety of OCD symptoms in patients. This test is not a diagnostic tool; however, it is a research tool for classifying patients with obsessive-compulsive symptoms. The four main classes of symptoms identified separately in the MOCI are checking, cleaning, slowness, and doubting. The test score is from 0-30, with higher scores indicating more obsessive-compulsive symptoms. The test validity is generally above $8 \%$ in all four classes. The test sensitivity is also low due to its double responses to changes. In Iran, Dadfar (quoted by Bavi \& Masodifar, 2015 ) reported a total validity of $84 \%$ for the test and its validity and convergence with the obsessive-compulsive scale of Yale-Brown (87\%). This questionnaire has good test-retest reliability and good internal validity. Its reliability coefficient using test-retest was 0.80 and internal validity was 0.70-0.80 (Rachman \& Hodgson, 1999). In Iran, Mahmoud Aliloo, Atefvahid, Bayanzadeh \& Malakouti (2005) estimated the reliability of this tool as 0.78 using the test-retest method. In the present study, Cronbach's alpha coefficient of this scale was obtained 0.79 . 


\section{Cognitive Flexibility Inventory (CFI)}

The Cognitive Flexibility Inventory developed by Dennis and Vander Wal in 2010, is a short 20-item self-report tool used to measure a type of cognitive flexibility needed in an individual's situation to challenge and replace inefficient thoughts with more efficient ones. Its scoring method is based on a 7-point Likert scale and measures three aspects of cognitive flexibility: A. The desire to understand difficult situations as controllable situations; B. The ability to understand several alternative justifications for human life and behavior events; and C. The ability to create multiple alternative solutions for difficult situations. Dennis \& Vander Wal showed in their research that this questionnaire enjoys a proper factor structure and convergent and simultaneous validity. It has indicated that the two factors of perception of different options and perception of behavior justification had the same meaning, and the control factor was considered as the second subscale.

The simultaneous validity of this questionnaire with the second edition of the Beck Depression Inventory (BDI-II) was -0.39 and its convergent validity with the cognitive flexibility scale of Martin and Rubin was 0.75 . The Cronbach's alpha reliability for the overall scale, controllability perception, and perception of different options were $0.91,0.91$, and 0.84 , respectively, and 0.81 , 0.75 , and 0.77 , respectively, using the retest method (Dennis \& Vander Wal, 2010). In Iran, Shareh et al. (Soltani, Shareh, Bahrainian \& Farmani, 2013) reported the overall retest validity coefficient of 0.71 for CFI and $0.55,0.72$, and 0.57 for the subscales of controllability perception, perception of different options, and behavior justification perception, respectively. These studies reported Cronbach's coefficients of 0.90 for the total scale and $.87,0.89$, and 0.55 for the subscales of controllability perception, perception of different options, and behavior justification perception, respectively (Soltani et al., 2013). In this study, Cronbach's alpha coefficient of this scale was obtained 0.81 .

\section{Student Social Cognition Questionnaire (SHAD)}

This questionnaire was developed by Nejati, Kamari \& Jafari (2018) to assess the status of social cognition assessment in students. The theoretical foundations of the theory of mind have been used to construct the tool, and the theoretical foundations of social cognition, which has the functions of self-awareness, the theory of mind, threat detection, and self-regulation, have been used to name its subscales (Todorov, Fiske \& Prentice, 2011). This 19-item questionnaire is scored on a 5-point Likert scale as follows: 1 . Almost never; 2. Rarely; 3 . Some- times; 4. Often; and 5. Almost always. The results of the factor analysis of the SHAD questionnaire, with the main components method along with the varimax rotation, showed the existence of four components of social cognition, named in order of self-knowledge, mind-reading, recognizing the educational threat, and understanding educational environment.

The Kaiser-Meyer Olkin index of this scale was equal to 0.845 and the Bartlett Sphericity coefficient was significant at 28.2491 with a degree of freedom of 171 at the significance level of 0.0001 , indicating the adequacy of sampling of the questionnaire. Also, in order to assess the reliability of the questionnaire, Cronbach's alpha coefficient, and the correlation of the subscales with the total score of the questionnaire were used. Cronbach's alpha coefficients were obtained for the subscales of selfknowledge $(0.73)$, mind reading $(0.72)$, educational threat detection (0.71), and comprehension of the educational environment (0.74), as well as the total questionnaire (0.86) (Nejati et al., 2018). In the present study, Cronbach's alpha coefficient of this scale was obtained 0.78 .

\section{Results}

The results of the descriptive statistics for all variables are presented in Table 1. The Mean \pm SD of the total number of participants in the study on the scales of MOCI was 12.11 (4.02), CFI was 85.59 (13.75), and SHAD was $50.38(9.67)$.

The results of the correlation coefficient between the research variables are reported in Table 2. As can be seen, there was a significant inverse correlation between obsessive-compulsive symptoms and the general score of cognitive flexibility $(\mathrm{P}<0.001, \mathrm{R}=-0.621)$ and the total score of social cognition $((\mathrm{P}<0.001,0=-0.554)$.

In order to test the normality of the data for each variable, the Kolmogorov-Smirnov test was used and its results showed the normal distribution of the data $(\mathrm{P}>0.05)$ For investigating the role of predictor variables (cognitive flexibility and social cognition) in predicting the criterion variable (obsessive-compulsive symptoms), the multivariate regression analysis method was simultaneously used and its results are listed in Tables 3 and 4 .

The obtained correlation coefficient between the two predictor variables and obsessive-compulsive symptoms $(\mathrm{r}=-0.653)$ and the $\mathrm{R}^{2}$ value of 0.426 indicated that approximately $42 \%$ of the variance of the obsessive-compulsive symptoms can be explained in students based on the cognitive flexibility and social cognition variables. 
Table 1. Description of the research variables in terms of central tendency index and dispersion

\begin{tabular}{cc}
\hline Variable & Mean \pm SD \\
\hline Obsessive - compulsive symptoms & $12.11 \pm 4.02$ \\
Cognitive flexibility & $85.59 \pm 13.75$ \\
Social cognition & $50.38 \pm 9.67$ \\
\hline & PLACTICE In PSYCH $\triangle$ LOGY
\end{tabular}

Table 2. Results of correlation analysis for the variables of cognitive flexibility, social cognition, and obsessive-compulsive symptoms

\begin{tabular}{ccc}
\hline The Predictor Variables & Statistics & Obsessive-compulsive Symptoms \\
\hline \multirow{2}{*}{ Cognitive flexibility } & The correlation coefficient & $-0.621^{* *}$ \\
& Significance level & 0.001 \\
Social cognition & The correlation coefficient & $-0.554^{* *}$ \\
& Significance level & 0.001 \\
\hline
\end{tabular}

** Significant at the level of 0.01 .

As can be seen in Table 3, the ratio of $F$ obtained for investigating the significance of the correlation coefficient was significant $(\mathrm{P}<0.001)$.

Based on Table 4, the variability of cognitive flexibility with a beta of $-0.434(\mathrm{P}<0.001)$ and the social cognitive variable with a beta of $-0.323(\mathrm{P}<0.001)$ can negatively predict the mean obsessive-compulsive symptoms. The obtained betas indicated that cognitive flexibility followed by social cognition had predictive power, respectively.

\section{Discussion}

Based on the results of the present study, cognitive flexibility and social cognition have a significant negative correlation with obsessive-compulsive symptoms. These results suggest that the higher a person's cognitive flexibility and social cognition, the lower the severity of obsessive-compulsive symptoms. Cognitive flexibility and social cognition were also able to explain $42 \%$ of the variance of obsessive-compulsive symptoms. These findings are consistent with the findings of Rosa-Alcázar et al. (2020), Bigdeli et al. (2017), Vaghi et al. (2017), Abramovich et al. (2013), Francazio \& Flessner (2015), and Misir et al. (2018). In the study by Rosa-Alcázar et al. (2020), a group of people with OCD showed lower scores in cognitive flexibility than the group with a generalized anxiety disorder and the control group.
The research by Bigdeli et al. (2017) also showed that people with OCD have poorer cognitive flexibility and working memory than normal students. In the study by Vaghi et al. (2017), the cognitive flexibility of people with OCD was significantly lower than the normal group. Abramovich et al. (2013) also examined the neuropsychology of OCD and concluded that these individuals had a poor performance in executive functions. In the research by Francazio \& Flessner (2015), the cognitive flexibility of young people with OCD was lower than that of healthy people. In Misir et al. (2018) study, patients with OCD also indicated significant impairment in the auditory-social and perceptual-social aspects of the theory of mind.

However, they were inconsistent with the studies by Mavrogeorgiue et al. (2016) and Simpson et al. (2006). Mavrogeorgiue et al. (2016) showed that there was no significant difference in the base social cognitive abilities of OCD patients compared with the control group. Simpson et al. (2006) also observed some differences in neuronal function between the OCD group and the healthy control group. According to Simpson et al. (2006), the inconsistency of obsessive-compulsive symptoms can be the reason beyond the differences in the results of cognitive flexibility studies in OCD, and also subtypes of OCD might have different cognitive profiles (e.g. contamination, checking, symmetry, and hoarding). 
Table 3. Analysis of the variance in the regression model to predict the obsessive-compulsive symptoms

\begin{tabular}{|c|c|c|c|c|c|}
\hline Source of Variation & Total Squares & df & Mean Squares & $\mathbf{F}$ & $\mathbf{P}$ \\
\hline Regression & 39465.302 & 2 & 21317.567 & 134.121 & 0.001 \\
\hline Residual & 49431.213 & 197 & 141.235 & & \\
\hline Total & 88978.835 & 199 & & & \\
\hline
\end{tabular}

Table 4. Results of regression coefficients

\begin{tabular}{|c|c|c|c|c|c|}
\hline \multirow{2}{*}{ Model } & \multicolumn{2}{|c|}{ Non-standard Coefficients } & \multirow{2}{*}{ Standard Coefficients (Beta) } & \multirow{2}{*}{$\mathbf{T}$} & \multirow{2}{*}{ Significance Leve } \\
\hline & B & SD & & & \\
\hline Constant value & 33.21 & 5.463 & - & 8.137 & 0.001 \\
\hline Cognitive flexibility & -0.634 & 0.072 & -0.434 & -7.315 & 0.0001 \\
\hline Social cognition & -0.556 & 0.067 & -0.323 & -6.834 & 0.001 \\
\hline
\end{tabular}

As mentioned earlier, in explaining the findings of this study, cognitive flexibility is defined as the individual's ability in inhibiting a dominant but inefficient and inappropriate response, and the ability to achieve more distant alternative responses. Therefore it is thought to include two sub-categories of inhibiting the irrelevant cases and transferring attention and concentration to different tasks or mental sets (Carbonella \& Timpano, 2016). Cognitive flexibility theory ( $\mathrm{Gu}$ et al., 2008) states that OCD patients have difficulty in changing thoughts or stimuli. For example, someone who suffers from OCD has an unpleasant thought, and has a lower ability to change it into a more enjoyable thought; therefore, that unpleasant thought is repeated leading to fear and stress. Because obsessive-compulsive behaviors are conducted to reduce or prevent fear and stress, these actions are repeated. Researchers explain this repetition by assuming that OCD patients naturally have a lower skill in changing different thoughts or stimuli (Gu et al., 2008). Studies have also shown that the frontal cortex plays a role in cognitive flexibility and it was proved that OCD affects this part of the brain (Menzies et al., 2008). Thus, obsessive-compulsive symptoms can be explained by cognitive flexibility problems, such as the ability to change focus.

Also, the poor performance of people with OCD symptoms may be associated with impairment in their cognitive and social-emotional abilities. As mentioned earlier, social cognition involves a set of cognitive processes about one's thoughts, attitudes, behaviors, and emotional issues, and those around oneself, where he argues about himself as a human being and his relationships with others (Cotter et al., 2018). Thus, any functional impairment or structural confusion under the neural layers, which involves cognitive capacity, can harm social functioning. According to neurobiological studies of social cognition, neural connections between the amygdala, anterior cingulate gyrus, superior temporal gyrus, and frontal areas are involved in social cognition. These areas include the area called the frontostriatal system, which is believed that it has no normal function in OCD patients (Sayın, Oral, Utku, Baysak \& Candansayar, 2010; Soriano-Mas \& Harrison, 2019).

The impairments in social cognition, especially those in the theory of mind in OCD individuals, may be explained by the metacognitive impairments observed in these individuals, meaning that their inability to think their own thoughts might be associated with difficulty in finding deductions about the mental states of others (Misir et al., 2018; Sayın et al., 2010). These flawed beliefs about one's thoughts may be associated with social cognition abilities. However, social cognitive impairments can be somewhat secondary towards the cognitive impairments in people with OCD symptoms because deterrence skills can be quite important, especially in perspective-taking and understanding multiple perspectives requires considering the beliefs as the future emotions or actions that control the one's knowledge (Bull, Phillips \& Conway, 2008). Response inhibition processes and cognitive set shifting can play a significant role in the argument of mental states (perspective-taking) (Misir et al., 2018). 
In conclusion, the present study faced some limitations, such as using a non-clinical and single-sex sample as well as using self-reporting tools to collect information. Using self-report questionnaires can be associated with the respondents' bias. Also, this study was cross-sectional, which limits the generalizability of the results. Because the sample group in this study was limited to female students, caution should be exercised in generalizing results to males, other age groups, and other levels of education.

Therefore, in future studies, it is suggested to use a clinical sample of both sexes in the research in order to compare the results. Also, in examining the hypothesis of Simpson et al., it is suggested to distinguish subtypes of OCD symptoms in studies. Because the findings in OCD cognitive etiology have yielded conflicting results; therefore, more empirical studies are needed to provide a more accurate scientific explanation. It is recommended that future studies be conducted on the pathology of obsessive-compulsive symptoms in different age groups. Also, cognitive and social flexibility along with other neurocognitive correlations of obsessive-compulsive symptoms should be considered in the future. Understanding the neurocognitive correlations of obsessivecompulsive symptoms will facilitate a better understanding of the factors associated with phenotypic forms of OCD and lead to better treatment for these symptoms.

\section{Conclusion}

Based on the results of the present study, the variables of cognitive flexibility and social cognition have a negative relationship with obsessive-compulsive symptoms, i.e. the OCD symptoms will be predictable by these two variables. Studying cognitive flexibility and social cognition is effective in understanding the underlying factors associated with the symptoms of OCD, and evaluating these factors can be beneficial in preventing and treating the symptoms of this disorder. According to the results of this study, educational programs based on cognitive flexibility and social cognition in the form of compressed and short-term workshops are recommended for all students, especially female students with obsessive-compulsive symptoms.

\section{Ethical Considerations}

\section{Compliance with ethical guidelines}

All ethical principles were considered in this article. The participants were informed about the purpose of the research and its implementation stages. They were also assured of the confidentiality of their information. Moreover, they were allowed to leave the study whenever they wish, and if desired, and the results of the research would be available to them.

\section{Funding}

This research did not receive any specific grant from funding agencies in the public, commercial, or non-profit sectors.

\section{Authors' contributions}

All authors contributed in preparing this article.

\section{Conflict of interest}

The authors declared no conflict of interest.

\section{Acknowledgments}

We appreciate all the officials and students of Allameh Tabataba'i University who contributed in this research.

\section{References}

Abbruzzese, M., Ferri, S., \& Scarone, S. (1997). The selective breakdown of frontal functions in patients with obsessive-compulsive disorder and in patients with schizophrenia: A double dissociation experimental finding. Neuropsychologia, 35(6), 907-12. [DOI:10.1016/S0028-3932(96)00095-4]

Abramovitch, A., Abramowitz, J. S., \& Mittelman, A. (2013). The neuropsychology of adult obsessive-compulsive disorder: A meta-analysis. Clinical Psychology Review, 33(8), 1163-71. [DOI:10.1016/j.cpr.2013.09.004] [PMID]

Aigner, M., Sachs, G., Bruckmüller, E., Winklbaur, B., Zitterl, W., Kryspin-Exner, I., \& et al. (2007). Cognitive and emotion recognition deficits in obsessive-compulsive disorder. Psychiatry Research, 149(1-3), 121-8. [DOI:10.1016/j.psychres.2005.12.006] [PMID]

American Psychiatric Association. (2013). Diagnostic and statistical manual of mental disorders (DSM-5). Washington, DC: American Psychiatric Association Publishing. [DOI:10.1176/appi. books.9780890425596]

Ardila, A. (2008). On the evolutionary origins of executive functions. Brain and Cognition, 68(1), 92-9. [DOI:10.1016/j. bandc.2008.03.003] [PMID]

Bannon, Sh., Gonsalvez, C. J., Croft, R. J., \& Boyce, P. M. (2006). Executive functions in obsessive-compulsive disorder: State or trait deficits? Australian $\mathcal{E}$ New Zealand Journal of Psychiatry, 40(11-12), 1031-8. [DOI:10.1080/j.1440-1614.2006.01928.x] [PMID]

Barlow, D. H. (2004). Anxiety and its disorders: The nature and treatment of anxiety and panic. New York: Guilford Press. https:// books.google.com/books?id=Lx9hf-3ZJCQC\&dq 
Bavi, S., \& Masodifar, M. (2015). [The relationship between components of primary maladaptive schemas and meta-cognitive beliefs with signs of obsessive-compulsive disorder among students (Persian)]. Middle Eastern Journal of Disability Studies, 5, 25160. http://jdisabilstud.org/article-1-573-en.html

Bigdeli, I., Badin, M., \& Sabahi, P. (2017). [The comparison of cognitive flexibility, theory of mind and working memory in students with symptoms of obsessive-compulsive disorder and normal group (Persian)]. Advances in Cognitive Sciences, 18(4), 24-37. http://icssjournal.ir/article-1-517-en.html

Bodden, M. E., Dodel, R., \& Kalbe, E. (2010). Theory of mind in Parkinson's disease and related basal ganglia disorders: A systematic review. Movement Disorders, 25(1), 13-27. [DOI:10.1002/ mds.22818] [PMID]

Bohne, A., Savage, C. R., Deckersbach, T., Keuthen, N. J., Jenike, M. A., Tuschen-Caffier, B., \& et al. (2005). Visuospatial abilities, memory, and executive functioning in trichotillomania and obsessive-compulsive disorder. Journal of Clinical and Experimental Neuropsychology, 27(4), 385-99. [DOI:10.1080/13803390490520418] [PMID]

Britton, J. C., Rauch, S. L., Rosso, I. M., Killgore, W. D., Price, L. M., Ragan, J., \& et al. (2010). Cognitive inflexibility and frontal-cortical activation in pediatric obsessive-compulsive disorder. Journal of the American Academy of Child \& Adolescent Psychiatry, 49(9), 944-53. [DOI:10.1016/j.jaac.2010.05.006] [PMID] [PMCID]

Shams, G., Karam Ghadiri, N., Esmaili, Y., Amini, H., Ebrahim Khani, N., \& Beferoni, N., et al. (2008). Prevalenceo obsessivecompulsive symptoms and its comorbidity with psychiatric symptoms in adolescents. Journal of Advances in Cognitive Sciences, 9(4), 50-9. http://www.magiran.com/p532295.

Bull, R., Phillips, L. H., \& Conway, C. A. (2008). The role of control functions in mentalizing: Dual-task studies of theory of mind and executive function. Cognition, 107(2), 663-72. [DOI:10.1016/j. cognition.2007.07.015] [PMID]

Burns, J. K. (2006). Psychosis: a costly by-product of social brain evolution in Homo sapiens. Progress in Neuro-Psychopharmacology and Biological Psychiatry, 30(5), 797-814. [DOI:10.1016/j.pnpbp.2006.01.006] [PMID]

Cameron, D. H., Summerfeldt, L. J., Rowa, K., McKinnon, M. C., Rector, N. A., Richter, M. A., \& et al. (2019). Differences in neuropsychological performance between incompleteness-and harm avoidance-related core dimensions in obsessive-compulsive disorder. Journal of Obsessive-Compulsive and Related Disorders, 22, 100448. [DOI:10.1016/j.jocrd.2019.100448]

Carbonella, J. Y., \& Timpano, K. R. (2016). Examining the link between hoarding symptoms and cognitive flexibility deficits. Behavior Therapy, 47(2), 262-73. [DOI:10.1016/j.beth.2015.11.003] [PMID]

Cotter, J., Granger, K., Backx, R., Hobbs, M., Looi, C. Y., \& Barnett, J. H. (2018). Social cognitive dysfunction as a clinical marker: A systematic review of meta-analyses across 30 clinical conditions. Neuroscience \& Biobehavioral Reviews, 84, 92-9. [DOI:10.1016/j. neubiorev.2017.11.014] [PMID]

Darvishi, N., Mahmoud Alilou, M., Bakhshipour, A., Farnam, A. R., \& Bahramkhani, M. (2013). [Theory of mind in obsessive-compulsive disorder patients versus normal individuals (Persian)]. Advances in Cognitive Sciences, 15(1), 77-89. http:/ /icssjournal.ir/ article-1-243-en.html
Deák, G. O., \& Wiseheart, M. (2015). Cognitive flexibility in young children: General or task-specific capacity? Journal of Experimental Child Psychology, 138, 31-53. [DOI:10.1016/j.jecp.2015.04.003] [PMID]

Delavar, A. (2000). Research method in psychology. Tehran: Ed, Virayesh. http://opac.nlai.ir/opac-prod/bibliographic/540880

Dennis, J. P., \& Vander Wal, J. S. (2010). The cognitive flexibility inventory: Instrument development and estimates of reliability and validity. Cognitive Therapy and Research, 34(3), 241-53. [DOI:10.1007/s10608-009-9276-4]

Forray, A., Focseneanu, M., Pittman, B. McDougle, C. J., \& Neill Epperson, C. (2010). Onset and exacerbation of obsessivecompulsive disorder in pregnancy and the postpartum period. The Journal of Clinical Psychiatry, 71(8), 1061-8. [DOI:10.4088/ JCP.09m05381blu] [PMID] [PMCID]

Francazio, S. K., \& Flessner, C. A. (2015). Cognitive flexibility differentiates young adults exhibiting obsessive-compulsive behaviors from controls. Psychiatry Research, 228(2), 185-90. [DOI:10.1016/j. psychres.2015.04.038] [PMID]

Ghafeleh Bashi, S. H., Sarichloo, M. E., Mousavi, S. A. M., \& Salehi, S. (2014). [Examined demographic characteristics and signs of obsessive-compulsive disorder (Persian)]. Journal of Sabzevar University of Medical Sciences, 21(2), 343-51. http://jsums.medsab. ac.ir/article_435.html

Ghamarigivi, H. (2013). [The investigation of the cognitive inhibition and recognition dificit in patients with obsessive-compulsive disorder (Persian)]. International Journal of Behavioral Sciences, 6(4), 315-21. http://www.behavsci.ir/article_67796.html

Gu, B. M., Park, J. Y., Kang, D. H., Lee, S. J., Yoo, S. Y., Jo, H. J., \& et al. (2008). Neural correlates of cognitive inflexibility during task-switching in obsessive-compulsive disorder. Brain, 131(1), 155-64. [DOI:10.1093/brain/awm277] [PMID]

Hashemloo, L., Safaralizadeh, F., Bagheriyeh, F., \& Motearefi, H (2014). [The prevalence obsessive-compulsive disorder in students in Khoy University in 2013 (Persian)]. Iranian Journal of Psychiatric Nursing, 2(2), 13-21. http:/ /ijpn.ir/article-1-329-en.html

Hekmati, I. (2012). [Comparison of executive functions in subclinical obsessive-compulsive disorder without depressive symptoms (Persian)]. International Journal of Behavioral Science, 6(1), 39-47. http:// www.behavsci.ir/article_67762.html

Kang, J. I., Namkoong, K., Yoo, S. W., Jhung, K., \& Kim, S. J. (2012). Abnormalities of emotional awareness and perception in patients with obsessive-compulsive disorder. Journal of Affective Disorders, 141(2-3), 286-93. [DOI:10.1016/j.jad.2012.04.001] [PMID]

Khosravi, S., \& Naseri, A. (2017). [Obsessive-compulsive prevalence investigation in Jahrom city (Persian)]. Pars Journal of Medical Sciences, 15(3), 1-8. http://jmj.jums.ac.ir/article-1-951-en.html

Lawrence, N. S., Wooderson, S., Mataix-Cols, D., David, R., Speckens, A., \& Phillips, M. L. (2006). Decision making and set shifting impairments are associated with distinct symptom dimensions in obsessive-compulsive disorder. Neuropsychology, 20(4), 409-19. [DOI:10.1037/0894-4105.20.4.409] [PMID]

Mahmoud Aliloo, M., Atefvahid, M. K., Bayanzadeh, S. A., \& Malakouti, S. K. (2005). [Memory problems in checking type obsessive-compulsive disorder (Persian)]. Iranian Journal of Psychiatry and Clinical Psychology, 11(1), 62-70. http://ijpcp.iums.ac.ir/ article-1-85-en.html 
Mavrogiorgou, P., Bethge, M., Luksnat, S., Nalato, F., Juckel, G., \& Brüne, M. (2016). Social cognition and metacognition in obsessive-compulsive disorder: an explorative pilot study. European Archives of Psychiatry and Clinical Neuroscience, 266(3), 209-16. [DOI:10.1007/s00406-016-0669-6] [PMID]

Menzies, L., Chamberlain, S. R., Laird, A. R., Thelen, S. M., Sahakian, B. J., \& Bullmore, E. T. (2008). Integrating evidence from neuroimaging and neuropsychological studies of obsessive-compulsive disorder: The orbitofronto-striatal model revisited. Neuroscience \& Biobehavioral Reviews, 32(3), 525-49. [DOI:10.1016/j. neubiorev.2007.09.005] [PMID] [PMCID]

Misır, E., Bora, E., \& Akdede, B. B. (2018). Relationship between social-cognitive and social-perceptual aspects of theory of mind and neurocognitive deficits, insight level and schizotypal traits in obsessive-compulsive disorder. Comprehensive Psychiatry, 83, 1-6. [DOI:10.1016/j.comppsych.2018.02.008] [PMID]

Moritz, S., Birkner, C., Kloss, M., Jacobsen, D., Fricke, S., Böthern, A., \& et al. (2001). Impact of comorbid depressive symptoms on neuropsychological performance in obsessive-compulsive disorder. Journal of abnormal psychology, 110(4), 653-7. [DOI:10.1037/0021843X.110.4.653] [PMID]

Moritz, S., Birkner, C., Kloss, M., Jahn, H., Hand, I., Haasen, C., $\&$ et al. (2002). Executive functioning in obsessive-compulsive disorder, unipolar depression, and schizophrenia. Archives of Clinical Neuropsychology, 17(5), 477-83. [DOI:10.1016/S08876177(01)00130-5] [PMID]

Movahedi, Y., Khodadadi, M., \& Mohammadzadegan, R. (2014). [The comparison cognitive function and theory of mind in people with symptoms of obsessive - compulsive disorder and normal people (Persian)]. Journal of Cognitive Psychology, 2(3), 28-36. http://jcp.khu.ac.ir/article-1-2395-en.html

Nejati, V., Kamari, S., Jafari, S. (2018). [Construction and examine the psychometric characteristic of student social cognition questionnaire (SHAD) (Persian)]. Social Cognition, 7(2), 123-44. [DOI:10.30473/SC.2018.29262.1931]

Okasha, A., Rafaat, M., Mahallawy, N., El Nahas, G., El Dawla, A. S., Sayed, M., \& et al. (2000). Cognitive dysfunction in obsessivecompulsive disorder. Acta Psychiatrica Scandinavica, 101(4), 281-5. [DOI:10.1034/j.1600-0447.2000.101004281.x] [PMID]

Ozcan, H., Ozer, S., \& Yagcioglu, S. (2016). Neuropsychological, electrophysiological and neurological impairments in patients with obsessive compulsive disorder, their healthy siblings and healthy controls: Identifying potential endophenotype (s). Psychiatry Research, 240, 110-7. [DOI:10.1016/j.psychres.2016.04.013] [PMID]

Pinkham, A. E., Penn, D. L., Green, M. F., Buck, B., Healey, K., \& Harvey, P. D. (2014). The social cognition psychometric evaluation study: Results of the expert survey and RAND panel. Schizophrenia Bulletin, 40(4), 813-23. [DOI:10.1093/schbul/sbt081] [PMID] [PMCID]

Purdon, C., \& Clark, D. A. (1993). Obsessive intrusive thoughts in nonclinical subjects. Part I. Content and relation with depressive, anxious and obsessional symptoms. Behaviour Research and Therapy, 31(8), 713-20. [DOI:10.1016/0005-7967(93)90001-B]

Rachman, S., \& Hodgson, R. (1980). Obessiosn and compulsions. Englewood cliffs. New Jersey: Prentice Hall. https://books. google.com/books?id=dNctcgAACAAJ\&dq
Reyhani, M. B., Kamari, S., Zarei, R., \& Nejati, V. (2017). [Social cognition and academic satisfaction: The mediating role of achievement emotions (Persian)]. Social Cognition, 5(2), 136-54. http:// sc.journals.pnu.ac.ir/article_3275.html

Riggs, D. S., \& Foa, E. B. (1993). Obsessive compulsive disorder. In D. H. Barlow (Ed.), Clinical handbook of psychological disorders: A step-by-step treatment manual (p. 189-239). New York: The Guilford Press. https:// psycnet.apa.org/record/1993-98942-005

Rosa-Alcázar, Á., Olivares-Olivares, P. J., Martínez-Esparza, I. C., Parada-Navas, J. L., Rosa-Alcázar, A. I., \& Olivares-Rodríguez, J. (2020). Cognitive flexibility and response inhibition in patients with obsessive-compulsive disorder and generalized anxiety disorder. International Journal of Clinical and Health Psychology, 20(1), 20-8. [DOI:10.1016/j.ijchp.2019.07.006] [PMID] [PMCID]

Saxena, S., \& Rauch, S. L. (2000). Functional neuroimaging and the neuroanatomy of obsessive-compulsive disorder. Psychiatric Clinics of North America, 23(3), 563-86. [DOI:10.1016/S0193953X(05)70181-7]

Sayın, A., Oral, N., Utku, C., Baysak, E., \& Candansayar, S. (2010). Theory of mind in obsessive-compulsive disorder: Comparison with healthy controls. European Psychiatry, 25(2), 116-22. [DOI:10.1016/j.eurpsy.2009.09.002] [PMID]

Sharp, C., Fonagy, P., \& Goodyer, I. (2008). Introduction. In P. Fonagy \& I. Goodyer (Eds.), Social cognition and developmental psychopathology. Oxford: Oxford University Press. [DOI:10.1093/ med/9780198569183.003.0001]

Simpson, H. B., Rosen, W., Huppert, J. D., Lin, S. H., Foa, E. B., \& Liebowitz, M. R. (2006). Are there reliable neuropsychological deficits in obsessive-compulsive disorder? Journal of Psychiatric Research, 40(3), 247-57. [DOI:10.1016/j.jpsychires.2005.04.004] [PMID]

Snyder, H. R., Kaiser, R. H., Warren, S. L., \& Heller, W. (2015) Obsessive-compulsive disorder is associated with broad impairments in executive function: A meta-analysis. Clinical Psychological Science, 3(2), 301-30. [DOI:10.1177/2167702614534210] [PMID] [PMCID]

Soltani, E., Shareh, H., Bahrainian, S. A., \& Farmani, A. (2013). [The mediating role of cognitive flexibility in correlation of coping styles and resilience with depression (Persian)]. Pajoohandeh, 18(2), 88-96. http:/ / pajoohande.sbmu.ac.ir/article-1-1518-en.html

Soriano-Mas, C., \& Harrison, B. J. (2019). Structural brain imaging of obsessive-compulsive and related disorders. In L. F. Fontenelle, M. Yücel (Eds.), A transdiagnostic approach to obsessions, compulsions and related phenomena (p. 74-84). Cambridge: Cambridge University Press. [DOI:10.1017/9781108164313.009]

Todorov, A., Fiske, S., \& Prentice, D. (2011). Social neuroscience: Toward understanding the underpinnings of the social mind. Oxford: Oxford University Press. [DOI:10.1093/acprof:o so/9780195316872.001.0001]

Vaghi, M. M., Vértes, P. E., Kitzbichler, M. G., Apergis-Schoute, A. M., van der Flier, F. E., Fineberg, N. A., \& et al. (2017). Specific frontostriatal circuits for impaired cognitive flexibility and goal-directed planning in obsessive-compulsive disorder: Evidence from resting-state functional connectivity. Biological Psychiatry, 81(8), 708-17. [DOI:10.1016/j.biopsych.2016.08.009] [PMID] [PMCID] 